\section{UKCPR}

University of Kentucky

Center for

Poverty Research

\section{Discussion Paper Series}

DP 2012-10

ISSN: 1936-9379

\title{
The Child and Adult Care Food Program and Food Insecurity
}

\author{
Colleen Heflin \\ Truman School of Public Affairs \\ University of Missouri \\ Irma Arteaga \\ Truman School of Public Affairs \\ University of Missouri \\ Sara Gable \\ Department of Nutrition and Exercise Physiology \\ University of Missouri
}

October, 2012

Preferred citation

Heflin,C., Arteaga, I. \& Gable, S., The Child and Adult Care Food Program and Food Insecurity. University of Kentucky Center for Poverty Research Discussion Paper Series, DP2012-10. Retrieved [Date] from http:// www.ukcpr.org/Publications/DP2012-10.pdf.

Author correspondence

Colleen Heflin, 229 Middlebush Hall, University of Missouri, Columbia, MO, 65211-6100; Email HeflinCM@missouri.edu; Phone: (573)882-4398 
The Child and Adult Care Food Program and Food Insecurity

\section{Colleen Heflin \\ Irma Arteaga \\ Sara Gable}

\section{University of Missouri}

September 14, 2012 


\section{INTRODUCTION}

High rates of food insecurity are a significant problem in the United States. It is currently estimated that more than 48.8 million people live in food insecure households, meaning that at some time during the previous year, they were unable to acquire or were uncertain of having enough food to meet basic needs due to inadequate household resources (Coleman-Jensen, Nord, Andrews, \& Carlson, 2011). Rates of food insecurity are substantially higher among those in households with incomes below the poverty line (40.2\%) and in households with children headed by a single woman (35.1\%). Levels of food insecurity increased across U.S. households in 2008 as a result of the "Great Recession" rising from around 11 percent in the 2005-2006 time period to the measured high of approximately 14.5 in 2008, where it remains as of the 2010 estimate.

From a developmental perspective, it is believed that food insecurity has cumulative effects at different stages of development beginning in the prenatal period (Bhattacharya \& Currie, and Haider 2004; Cook \& Frank, 2008; Duncan, Brooks-Gunn \& Klebanov, 1994; Pollit, 1994; Morgane, Austin-LaFrance, Bronzino, et al., 1993; Scholl, Johnson, 2000). During infancy, hunger has negative effects during the period of neurodevelopment. Controlled experiments with animals suggest that hunger results in irreversible damage to brain development such as that associated with the insulation of neural fibers (Yaqub, 2002). The damage associated with a lack of nutritional intake accumulated during the first 2 years of life includes susceptibility to infections, slowed cognitive development and physical growth, susceptibility to chronic diseases, and a higher risk of delivering low-birth weight babies. Other non-health related problems include reduced school performance, increased school dropout and reduced productivity during adulthood (Hoddinott, Beherman, Maluccio, Flores \& Martorell, 2008). 
Prior literature has largely neglected the contributions of the Child and Adult Care Food Program (CACFP) to household food security. There are few studies that evaluate the impact of participation in CACFP on child and household food security (Gordon et al. 2010; Korenman et al. 2012). This is surprising given the impact that nutritional inadequacy can exert on early developmental processes. Furthermore, since CACFP receipt is tied to child care, the program may be an indirect work support in that it is a nutritional subsidy that is primarily accessed by children attending child care, when parents are presumably working in the formal labor market. In what follows, we explain the CACFP program in detail and review prior research examining CACFP participation. Then we describe our data and methods for each of our research questions. Using data from the Early Childhood Longitudinal Study Birth Cohort we examine the association between CACFP provider participation and the administrative location of the state CACFP program on food security status. We find that accessing child care through either a family care or center care provider who participates in CACFP is a marker for food insecurity. Additionally, we find that children who attend Head Start in states that administratively house the CACFP within the state department of education have a lower overall risk of food insecurity. In the final section, we discuss these findings and their limitations.

\section{The Child and Adult Care Food Program (CACFP)}

The Child and Adult Care Food Program (CACFP) provides cash reimbursement to family day care, child care centers, homeless shelters, and after-school programs for meals and snacks served to children. While adults and school-aged children are eligible, the large majority of funding through this program is directed towards younger children. In 2009, 3.2 million children participated (versus 112,000 adults). Except in special circumstances, children older than age 12 are not eligible to participate. Overall, participation is on the level of the Summer 
Food Service Program, and is dwarfed by participation in the National School Lunch Program, which had 31.7 million participates in 2010 (USDA 2012).

Figure 1 shows the number of meals served in child care centers and in home day-cares. From 1969 to 1976 meals were only served in centers and the number of meals served in centers increased sharply across the time period. After meals in homes were introduced, however, the number of meals served in homes increased more rapidly than the number served in centers and in 1990 home meals surpassed center meals. In 1997 the number of meals served in homes was surpassed by meals served in centers again. Since then, the number of meals served in centers has continued to grow while the number of meals served in homes has steadily decreased (USDA 2012). In fiscal year 2008, the last year for which published data are available, 2.3 million children participated across 49,624 child care centers. Additionally, another 849,000 children participated in 141,535 family child care homes (FRAC 2009).

Participation in CACFP is open to most child care providers ${ }^{1}$ and all children, but reimbursement rates vary depending on the type of care provided (center versus home and if licensed and for-profit), the income level of the neighborhood, provider and family income of the children. In child care centers a reimbursement scheme parallel to that of the National School Lunch Program is used in which meals and snacks served are reimbursed at three payment levels tied to the family income of the children (sometimes termed free meals, partial meals, paid meals). For family care providers, there are two levels of reimbursement that are determined by a mix of neighborhood, provider and family income. For the purposes of CACAFP participation, children are eligible if they reside in households with income below $185 \%$ of the federal poverty line or if they are part of a household that receives SNAP or TANF.

\footnotetext{
${ }^{1}$ For profit centers that serve few poor children (less than $25 \%$ of enrolled students) are the only group ineligible for any payment.
} 
Given these wide eligibility criteria that renders the majority of child care providers eligible and the tight operating margins of child care, it is interesting to note the wide variation in CACFP coverage at the state level. In Figure 2, we present the ratio of the total number of CACFP participants divided by the total number of children in poverty under age 5 by state for 2009. It is important to note that this is only a "back of the envelope" calculation as the total attendees will include a small number of older children and adults that participated in CACFP. Additionally, the number of children living below the poverty line below the age of 5 is not the universe of children eligible for CACFP since income eligibility extends to $185 \%$ of the poverty line and households receiving SNAP or TANF. Both of these errors in identifying the correct population should operate to positively bias the coverage of CACFP. As a result, coverage rates shown extend beyond $100 \%$. However, Figure 2 clearly shows wide levels of state variation in CACFP coverage. CACFP participation in states at the low end of the spectrum (Nevada, Arizona, Idaho, and South Carolina) are below $40 \%$ of the children living in poverty, even with the positive bias noted. In contrast, there are a group of states (North Dakota, Minnesota, Nebraska, and Wyoming) with very high levels of estimated participation among eligible populations. This wide level of state variation suggests that the administration of the CACFP program may vary in ways that are important for program outcomes.

While eligibility for CACFP participation is determined at the federal level, states have great discretion in how to administer CACFP. Administratively, CACFP is most often housed in the state department of education, the same state office that usually administers the National School Lunch Program. This typical arrangement is found in 38 states. However, given that CACFP is a means-tested program, 10 states have placed CACFP in state health and social service departments. Two others (Texas and New Jersey), perhaps focusing on the origin of the 
funds, place administrative responsible for CACFP in the state departments of agriculture.

Despite the previous literature indicating that organizational cultures vary between state agencies (Stearns and Almeida 2004; Sullivan and Messmer 2003) there has been no prior investigations in the extant literature, of which we are aware, into the possible impact of the importance of these administrative arrangements on CACFP outcomes.

Previous research on CACFP has focused on modeling participation in CACFP at the provider level (Kapur, Kilburn and Fair 1999) and child level (Gordon et al 2010). Participation is more likely among poor children who reside in low-income areas than among poor children in wealthier areas as well as among children who spend more time in care with lower socioeconomic status. Providers are more likely to participate if they are large, licensed, accredited, non-profit and connected to Head Start (Gordon et al 2010). Significant variation in participation among eligible providers by state also exists (Kapur, Kilburn and Fair 1999). Recent effort has focused on identifying barriers to delivering healthy food within child day care settings using CACFP (Institute of Medicine 2012; Institute of Medicine 2011).

Korenman and colleagues (2012) and Gordon and colleagues (2010) explore the nutritional consequences for participation in CACFP. Gordon et al. find that CACFP participation is associated with higher consumption of milk, vegetables, and fruit and a lower incidence of underweight among a sample of low-income 4 year old children enrolled at nonHead Start centers. No association was found between CACFP participation and overweight status or food insecurity at the child or household level. A significant limitation of this study is that it only examines CACFP participation among low-income children who attend child care centers: however, many participants access CACFP through family care and through Head Start. Additionally, since CACFP operates as a direct subsidy to the organization, the program benefits 
are likely to be spread throughout the entire client base of the center, regardless of the income level of the children who attend. Unlike the school setting in which children routinely eat different meals (i.e. either food from home or food purchased at the school cafeteria), child care settings typically serve the same food to all children who are present. Thus, meal reimbursements and nutritional guidelines for CACFP reimbursed meals are likely to benefit all the children enrolled at the center and not just low-income children. Korenman et al (2012) address some of these limitations by extending their analysis to include children in both Head Start and non-Head Start center care. However, Korenman et al. continue to exclude children in family day-care settings from their analysis and they are also eligible to participate in CACFP. More importantly though, Korenman et al. use a non-standard definition of food insecurity in which households who endorse any of the eighteen items in Food Security Module are considered to be food insecure, instead of the standard cut-off of three endorsed items. As a consequence, Korenman et al.'s findings are not comparable to others in the field. We address these limitations in the current study by extending our analysis of the effects of provider participation in CACFP on the full sample of children participating in child care settings, Head start and family care settings using the standard measures of food insecurity.

While studies of the relationship between CACFP participation and child outcomes are scarce, evaluations of WIC and the Food Stamp program may provide some guidance. Several studies have demonstrated that WIC recipients benefit from participation across a range of outcomes beginning with pregnancy and birth outcomes, improved iron status among preschoolers, lowered prevalence of iron-deficiency anemia among young children, and reduced levels of household food insecurity and food insecurity with hunger (Cook, Frank, Levenson et 
al., 2006; Lee, Mackey-Bilaver \& Chin, 2006; Kennedy, Gershoff, Reed \& Austin, 1982; Bitler and Currie 2005; Metallinos-Katsaras et al. 2010).

There are several additional studies that examine the relationship between food insecurity and participation in the Food Stamp program. A rigorous study that controls for endogeneity of food stamp program participation with an instrumental variable approach and analyzes the relationship between Food Stamp program participation and household food insecurity suggests that participation in the Food Stamp program reduces the severity of food insecurity (Yen et al., 2008). Similarly, using a logistic regression method, Cook and coauthors (2006) found that receipt of food stamps reduces negative child health consequences among food insecure families, reduces hospitalization, and leads to a 25 percent reduction in the likelihood of household food insecurity. However, issues with negative selection into food stamps and measurement error in reports of food stamp participation have created identification problems in evaluating the treatment effect of program participation (Gundersen, Joliffe and Tiehan 2009; Gundersen and Kreider 2007; Gibson and Foster 2006).

Drawing upon the prior research indicating positive impacts of participation in WIC and the Food Stamp program, we explore the contribution of the CACFP program to food insecurity. More specifically, we estimate the direct effect of provider participation in the CACFP program on household and child food insecurity of all income levels. We also explore the role of state institutional arrangements of the CACFP program on food security.

\section{DATA AND METHODS}

Our data come from the Early Childhood Longitudinal Study - Birth Cohort (ECLS-B). The ECLS-B includes a nationally representative sample of children born in 2001 and utilizes a multi-reporter, multi-method design to gather extensive information about children's home and 
educational experiences, including child care, from birth through kindergarten entry. About 10,700 parents and children participated at study initiation (i.e., child age 9-months); subsequent data collections occurred when children where approximately 24-months-old, 4-years-old, and at kindergarten entry. The ECLS-B contains a wealth of information including the core food security module, parent(s)' demographic background, family utilization of federal assistance (including SNAP and WIC), household income and composition, and detailed parent and provider reports concerning the study child's child care arrangements (including child care program reports of CACFP participation). We will focus our analysis on the 4 year-old sample.

Little is known about the role of the Child and Adult Care Food Program in the household food security status of families with children of preschool age, partly because of difficulty identifying participating providers. Unlike most food and nutrition programs, parent often have no reason to know if their provider is participation in CACFP and so parental reports are unreliable. A distinct strength of the ECLS-B is that CACFP participation data were gathered from child care program directors and home day-care providers, thus reducing the type of measurement error one might expect from parent reports of CACFP participation (Gundersen and Kreider 2009).

To assess the relative importance of CACFP participation on child and household food insecurity during the preschool years, we estimate the following model:

(1) $Y_{i}=\alpha_{i}+X_{i} \beta+Z_{i} \delta+\mu Y_{t-1}+\varepsilon$

Where $\mathrm{Y}_{\mathrm{i}}$ indicates a measure of food security for household $i, X_{i}$ identifies participation on CACFP for the child care provider for household $i$ and if the administrative location of CACFP is in the state department of education, $\beta$ is a vector of estimated coefficients associated with $\mathrm{X}, \mathrm{Z}_{\mathrm{i}}$ includes demographic, household composition, labor force participation and other characteristics that prior literature has indicated are associated with food security status, $\delta$ is a 
vector of estimated coefficients associated with $Z$, and $\varepsilon$ is a normally distributed error term with constant variance and mean of 0 . We also include a measure of food insecurity at the 4 year old interview, $Y_{t-1}$. This lagged dependent variable helps to control for unobserved factors associated with food insecurity in the prior time period.

One potential problem with the model shown in (1) is that differences in the population of children who receive care in child care arrangements that participate in CACFP are likely to be different from children who do not receive care in CACFP participating centers. Therefore, as a sensitivity analysis, we estimate our results by using participation in CACFP as the treatment group and by creating a comparison group through the use of inverse propensity weighting. In an ideal world (randomized experiment) children would have been randomly assigned to CACFP participating centers; in this ideal world all CACFP children have the same probability of participating in a CACFP center. Propensity score weighting resembles a randomized experiment by reweighting the sample so that children with higher estimated probabilities of participating in CACFP are given smaller weights. As a result, children with overrepresented CACFP status, given the covariates, get smaller weights. Similarly, children are assigned larger weights if children have smaller estimated probabilities (propensity scores) of participating in CACFP. This method relies on the assumption that the researcher is able to observe the main variables that influence the probability of CACFP participation. Additional covariates included in the propensity score regressions that have been shown to be associated with CACFP participation (Gordon et al. 2010) include if the child care provider operates as a for-profit organization (versus a non-profit organization), if the child care provider is licensed, if the child care provider accepts state subsidies, if the child care provider is accredited and if the child is in care more than 30 hours or more. The propensity score, $\mathrm{p}$, is an estimate for the conditional probability of 
finding the child who participated in CAFP given a set of covariates. Children who participated in CACFP receive a weight equal to $1 / \mathrm{p}$; and children who did not participate in CACFP receive a weight $1 /(1-p)$.

Similar to propensity score matching, children that participate in CACFP (treatment group) are then compared with children that do not participate in CACFP that are most similar (comparison group) (Gibson and Foster 2007).

For each of our models, we will present results for four different groups of children. First, we look at the full sample of children in the sample and estimate the impact of CACFP participation and if the state houses CACFP within the state department of education. Then, we break the sample into three types of care: family day-care, center care (non-Head Start), and Head Start.

We will consider the impact of program participation of CACFP on measures of both child and household-level food security status. It has been documented that direct measures of low food security among children are lower than household measures of very low food security. Qualitative reports suggest that children may be buffered from the reduced food intake by other adults in the households (Polit, London, \& Martinez, 2001). Thus, participation in food and nutrition programs that increase the supply of food to children may be observed to affect not only the food security status of the child participating, but may also increase the food consumed by adults in the household. As a consequence, all our analyses will explore the effects of program participation on the food security status of both children specifically, and the household more generally.

Our measures of food security status are based on the USDA's 18 item Food Security Module. Eighteen questions are considered in order to rate food security for households. Using 
validated cut-points, we consider a household to be food secure if 0 to 2 items in the scale were answered affirmatively (this category is often referred to as high and marginal food security). If three or more items were answered affirmatively, we consider a household to be food insecure (USDA considers three different categories: food insecurity without hunger, moderate food insecurity and severe food insecurity). The last outcome corresponds to food security for children. Eight questions are considered to rate food security for children, questions that refer specifically to children. Using validated cut-points we consider that there is no evidence of food insecurity among children if one or none item in the scale was answered affirmatively. On the contrary, if two or more items were answered affirmatively, we consider that there is clear evidence of food insecurity among children (Nord, 2009).

Our control variables include a set of child and parental characteristics that have been found to be correlated with food security status in the extant literature. For child characteristics we include the child's age in months, gender, global self-rated health status and race (Black, Hispanic, Asian, mixed, and other versus White). For parental characteristics we include measures for maternal age in years, maternal education level (less than high school, more than high school and college versus high school degree), marital status (1=married versus not married), household income level (measured in categories), the number of household members less than 18 present, the number of household members 18 and over present, region (Midwest, South, West versus East) and urbanity (1=metropolitan area residence versus all others). Table 1 presents descriptive statistics for the full sample and by child care arrangement.

\section{RESULTS}

In Table 2 we show results of logistic regression models of the probability of reporting household and child food insecurity as a function of provider participation in CACFP, if CACFP is administratively housed with the state department of education, and a set of child and 
household level characteristics that have been found to be related to food security in the prior literature. The top half of the panel shows the results without correction for selection and the bottom half shows result with the Inverse Probability Weighting correction. Beginning with the first set of columns in Table 2, we show results for models which include a variable indicating the child is in child care but we do not control explicitly for the type of care. We find that going to a child care provider that participates in CACFP has no effect on the observed risk of either household or child level food insecurity. However, we do find that children that live in states that place administrative responsibilities for CACFP in the department of education are all at a lower risk of household food security. This result suggests that there may be positive externalities that exist from the administrative placement of CACFP that extend beyond the reach of program participation itself.

Next, we examined children in home day-care settings (both relative and non-relative care) and we see that children in this setting are at a higher risk for childhood food insecurity if the provider participated in the CACFP program. This suggests that children in home day-care settings whose providers participate are more likely to have unmeasured characteristics that place them at risk of childhood food insecurity. The administrative setting of CACFP, however, is not associated with the risk of either household or child food insecurity for children in home day care settings in models controlling for the common set of variables associated with food insecurity and reported food insecurity at age 2 .

Next, we turn to results for non-Head Start center-based care and we find that children in center based care in which the provider participates in CACFP have an increased log odds of experiencing household-level food insecurity. Children in center-based care are relatively advantaged relative to children that are not in child care at age 4: parents of children who use 
center care are more likely to be married, have higher incomes and education levels, all factors that lower the household risk of food insecurity. However, within this group of children attending center care, our results suggest that going to a provider that participates in CACFP is a marker for food insecurity. For children who attend for-profit centers, this certainly makes sense as the only way that for-profit centers can qualify is by serving $25 \%$ or more of their clients from low-income households. However, the majority of child care centers operate as non-profits and eligibility guidelines are quite generous for this group of centers.

Finally, in the last set of columns we present the results for children that attend Head Start. Here we find no effect of provider participation in CACFP, which is expected since all Head Start providers are categorically eligible to participate and 85 percent report participating. However, we find that there is a strong negative effect on the administration location of CACFP program: children that live in states where CACFP is located within the department of education have lower risks of household level food insecurity, controlling for household level food security status at age 2, child and household characteristics.

In the bottom half of Table 2, we report results of our analysis with Inverse Probability Weighting correction for selection. We find that our results are substantively quite similar to those in the top half of Table 2 but the statistical significance has become attenuated to the extent that many results which were marginally significant without the selection correction are now no longer significant. The attenuation of our results suggests that our variables of interest, CACFP participation and CACFP agency location, are correlated with many observable characteristics of households or child care providers. It is interesting to note that among the Head Start sample, children who attend centers in which the provider acknowledged participation in the CACFP program have a lower probability of reporting childhood food insecurity. Additionally, we 
continue to observe that children that attend Head Start in states that locate their CACFP agencies within the department of education have a lower risk of reporting household food insecurity.

\section{Sensitivity Analyses}

While findings shown in Table 2 are for the full set of children in our sample, we also ran a set of sensitivity analyses in which we replicated the models shown for the sample with household incomes below $185 \%$ of the poverty line. The patterns of significance are identical to those presented here with the one exception that among the family day-care sample, participation in CACFP is associated with an increase in both household and child food insecurity. Substantively, the findings for the low-income sample are stronger than those for the full sample. This finding suggests that the results shown in the full sample are probably attenuated by high income households and the main effects are being driven by low-income households.

We also replicated our analysis in Table 2 on our sample of households with children with the more restrictive measure of "food insecurity with hunger", also known as "very low food security". In our analysis with this different measure, our results were quite different. (See Appendix 1.) CACFP participation was not associated with very low food security for those with any care arrangement or for subgroups of children in family day-care, center care or Head Start.

Furthermore, we find that when CACFP is housed in the state department of education, there is a marginally significant positive association with very low food security for children who access child care through child care centers. This finding is in sharp contrast to the results shown in Table 2 and is likely driven by the small sample size of households with low food security, although we cannot rule out the presence of confounding factors.

\section{DISCUSSION}


The CACFP program is an under-researched piece of the national food assistance bundle of programs available to low-income households. Participation in CACFP is at the provider level and is open to all family care providers, all Head Start providers, all non-profit center care providers and for-profit center cares that serve a substantial low-income population. Participating providers receive reimbursements for meals served and the level of reimbursement works similarly to that for the National School Lunch Program in that it depends on the household income of children served. Substantively, variation exists at the state level in terms of the coverage and administrative placement of the CACFP program. While 38 states administer CACFP from within the state department of education, ten states administer CACFP with their other means-tested programs and 2 states place CACFP within the state department of agriculture.

We use nationally representative data from the ECLS-B to examine the relationship between provider participation in CACFP and food security status. Using logistic regression and models that include child characteristics, household characteristics and a lagged dependent variable to control for unmeasured characteristics that might be correlated with the probability of being food insecure at a prior time period, we estimate separate models for the full sample and by child care provider setting — family care, center care, and Head Start. We find that attending a child care setting that participates in CACFP has no effect on the observed risk of being food insecure for the full sample and Head Start sub-sample. However, we do find that children in family care settings have a higher risk of experiencing childhood food insecurity if the provider participates in CACFP relative to similar children whose family care provider does not participate in CACFP. Similarly, we also find that 
We also find that the location of the CACFP office within state agencies is related to household food insufficiency for children in Head Start. One possible explanation is that placing CACFP within state departments of education places an emphasis on the universal aspects of the CACFP program in terms of providing financial assistance to early childhood educators, while other arrangements place the program within a package designed to serve needy populations, which are often associated with a high level of social stigma. Another possibility is that there may be administrative efficiencies that are gleaned from placing the CACFP program and the NSLP program in the same agency since bureaucratic processes for reimbursement are quite similar.

Our study has several limitations worth noting. First, while our lagged dependent variable models nicely control for unobserved factors related to food security status at age 2 , changes in these conditions that occur between age 2 and 4 are not included in the model. For example, while we control for the base effect of marital status, changes in marital status are not incorporated into our model. This basic endogeneity problem is one that the reader can judge for themselves as to how problematic it is for our findings. Second, while we find interesting ameliorative effects of locating CACFP administrative offices with the state departments of education on all children in Head Start settings, we cannot rule the possibility that it may be that other state-level factors associated with this administrative choice are improving the food security of Head Start enrollees.

Given the growing body of evidence on the detrimental effects of nutritional deficiencies in early childhood, our study suggests that family day-care providers and child care centers that participate in CACFP may provide efficient intervention points for nutrition focused interventions. Indeed, it is worth nothing that Head Start centers, which have an explicit 
although sometimes unfilled mission to improve the nutritional intake of the children in their care, are the only setting in which we find a protective effect of CACFP when the program is located within a state department of education. This finding clearly suggests that there are important features of the context in which CACFP operates that should be the focus of future research. 


\section{REFERENCES}

Bhattacharya, J., Currie, J, and Haider, S. (2004). Poverty, food insecurity, and nutritional outcomes in children and adults. Journal of Health Economics 23:839-862.

Bitler, M., and Currie, J. (2005). "Does WIC Work? The Effects of WIC on Pregnancy and Birth Outcomes." Journal of Policy Analysis and Management 24 (1): 73-91.

Bitler, Marriane P., Craig Gundersen, and Grace S. Marquis. 2005. "Are WIC Nonrecipients at Less Nutritional Risk Than Recipients? An Application of the Food Security Measure." Review of Agricultural Economics 27 (3): 433-438.

Coleman-Jensen, A., Nord, M., Andrews, M., and Carlson, S. (2011). Household Food Security in the United States, 2010, Economic Research Report. Washington, D.C.: Economic Research Service, United States Department of Agriculture.

Cook, J., and Frank, D. (2008). Food security, poverty, and human development in the United States. Annals of the New York Academy of Science, 40: 1-16.

Duncan, J.,Brooks-Gunn, J., and Klebanov, P. (1994). Economic deprivation and early childhood development. Child Development 65: 296-318.

Dunifon, Rachel and Lori Kowaleski-Jones. (2003). The Influences of Participation in the National School Lunch Program and Food Insecurity on Child Well-Being. The Social Service Review, 77(1): 72-92 .

Gibson-Davis, Christina and E. Michael Foster. 2006. A Cautionary Tale: Using Propensity Scores to Estimate the Effect of Food Stamps on Food Insecurity. Social Service Review, Vol. 80 (1): 93-126.

Gordon, Rachel, Robert Kaestner, Sanders Korenman and Kristin Abner. 2010. "The Child and Adult Care Food Program: Who is served and what are their nutritional outcomes?" NBER Working Paper 16148.

Gundersen, C., and J. Gruber. (2001). The dynamic determinants of food insufficiency. Second Food Security Measurement and Research Conference, Volume II: Papers. M. Andrews and M. Prell, eds. pp. 92-110. Washington DC: U.S. Department of Agriculture, Economic Research Service, Food Assistance and Nutrition Research Report 11-2.

Gundersen, C, D. Joliffe, and L. Tiehen. 2009. The challenge of program evaluation: when increasing program participation decreases the relative well-being of participants. Food Policy. 32: 367-376.

Gundersen, C., and Kreider, B. (2009). Bounding the effects of food insecurity on child health outcomes. Journal of Health Economics, 28: 971-983

Heflin, C., Corcoran, M., and Siefert, K. (2007). Work Trajectories, Income Changes, and Food Insufficiency in a Michigan Welfare Population. Social Service Review, 81(1):3-25 
Hoddinott, J., Beherman, J., Maluccio,J., Flores, R., and Martorell, R. (2008). Effect of a nutrition intervention during early childhood on economic productivity in Guatemalan adults. The Lancet, 371 (9610): 411-416.

Jacknowitz, A., and Tiehen, L. (2009). Transitions into and out of the WIC Program: A Cause for Concern? Social Service Review, 83(2):151-183.

Kapur, Kanika, M. Rebecca Kilburn and C. Christine Fair. An Analysis of the Child and Adult Care Food Program in Child Care Centers. Santa Monica, CA: RAND Corporation, 1999. http://www.rand.org/pubs/monograph_reports/MR1167z0.

Korenman, Sanders, Kristin Abner, Robert Kaestner, and Rachel Gordon. 2012. "The child and adult care food program and the nutrition of preschoolers." Early Childhood Research Quarterly.in press.

Kreider, B., Pepper, J., Gunderson, C., and Jolliffe, D. (2009). Identifying the effects of food stamps on child health outcomes when participation is endogenous and misreported. Department of Economics Working paper No. 09023. Ames: University of Iowa.

Metallinos-Katsaras, Elizabeth, Kathleen Gorman, Parke Wilde and Jan Kallio. 2010. A Longitudinal Study of WIC Participation on Household Food Insecurity. Maternal and Child Health Journal.

Morgane, P., Austin-LaFrance, R., Bronzino, J. et al. (1993). Prenatal malnutrition and development of the brain. Neuroscience Bio-behavior Review 17: 91-128.

Nord, Mark. September 2009. Food Security in Households Children: Prevalence, Severity, and Household Characteristics. US Department of Agriculture. Economic Research Service. Economic Information Bulletin Number 56.

Institute of Medicine. 2012 "Research Methods to Assess Dietary Intake and Program Participation in Child Day Care: Application to the Child and Adult Care Food Program: Workshop Summary." Washington, DC: National Academies Press.

Institute of Medicine. 2011 "Child and Adult Care Food Program: aligning dietary guidance for all" Washington, DC: National Academies Press.

Pollit, E. (1994). Poverty and child development: relevance of research in developing countries to the United States. Child Development 65: 997S-1001S.

Ribar D, and Hamrick K. (2003). Dynamics of poverty and food sufficiency. Economic Research Service, Food Assistance and Nutrition Research Report, 33, Washington (DC): U.S. Department of Agriculture. 
Rose D. (1999). Economic determinants and dietary consequences of food insecurity in the United States. Journal of Nutrition, 129 (25 suppl):517S-520S

Rose D, and Oliveira V. (1997). Food insecurity and the intra-household distribution of nutrients. Presented at: the annual meeting of the Society for Nutrition Education; July 24-26, Montreal, QC, Canada.

Roustit,C,, Hamelin, A.M., Grillo, F., Martin, J., and Chauvin, P. (2010). Food Security: Could School Food Supplementation Help Break Cycles of Intergenerational Transmission of Social Inequalities? Pediatrics. 126(6): 1174-1181.

Stearns, Linda Brewster and Paul D. Almeida. The Formation of State Actor-Social Movement Coalitions and Favorable Policy Outcomes. Social Problems, Vol. 51, No. 4 (November 2004), pp. 478-504

Sullivan, Todd L. and Terry A. Messmer. Perceptions of Deer-Vehicle Collision Management by State Wildlife Agency and Department of Transportation Administrators. Wildlife Society Bulletin, Vol. 31, No. 1 (Spring, 2003), pp. 163-173

Turner, L., Chaloupka, F. J., Chriqui, J. F., \& Sandoval, A. (2010). School policies and practices to improve health and prevent obesity: National elementary school survey results: School years 2006-07 and 2007-08. Chicago, IL: Bridging the Gap Program, Health Policy Center, Institute for Health Research and Policy, University of Illinois at Chicago.

Scholl, T., and Johnson, W. (2000). Folic acid: influence on the outcome of pregnancy. Medical Journal of Clinical Nutrition, 71:1295S-1303S.

Yaqub, S. (2002). Chronic poverty: scrutinizing estimates, patterns, correlates, and explanations. CPRC Working Paper 21. Manchester: IDPM, University of Manchester. 


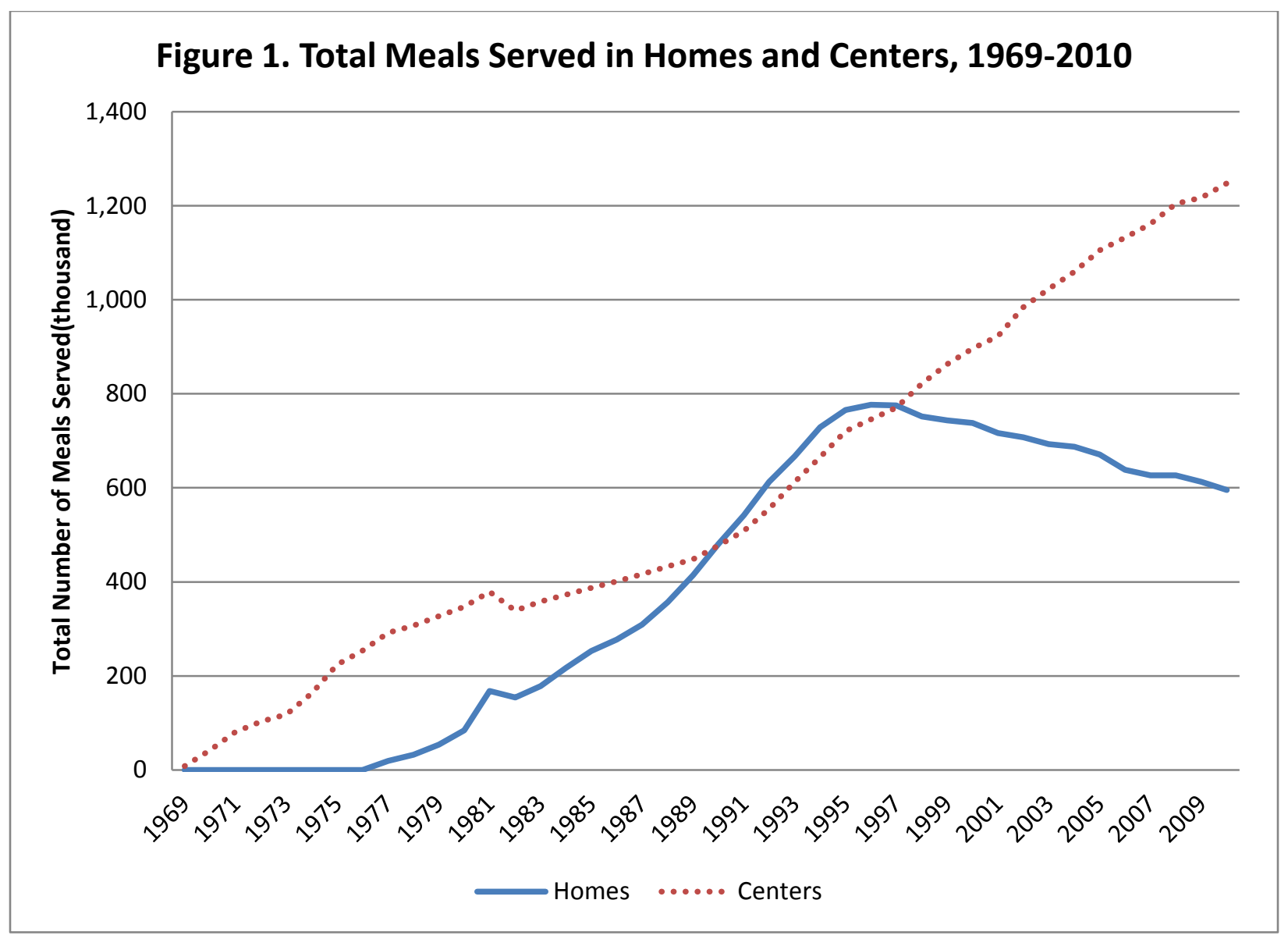




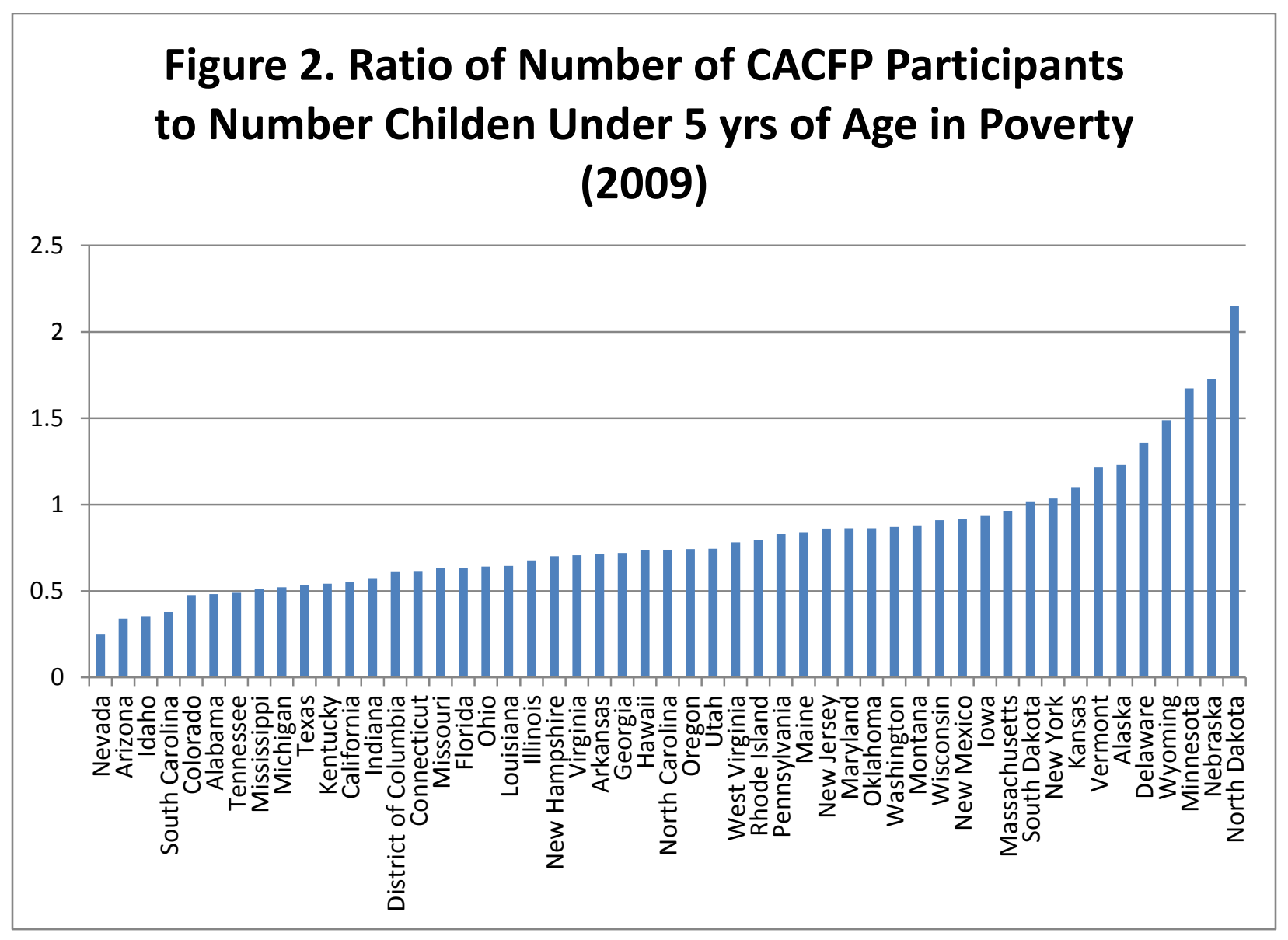


Table 1. Descriptive Statistics

Variables
Household Food Insecurity in wave 3

Food Secure

Food Insecure

Child Food Insecurity in wave3

Food Secure

Food Insecure

Household Food Insecurity in wave 2

Food Secure

Food Insecure

CACFP Participation

No Participation

Participation

Department location of CACFP Program

Other department

Department of education
Full Sample Family Care

Child's Race

White

Black

Hispanic

Asian

Mixed and other

Child's Gender

female

male

Child's Health Status

Excellent

Very Good

Good

Fair

Poor

44.93
87.66

12.34

97.35

2.65

90.84

9.16

63.05

36.95

43.85

56.15

87.23

12.77

97.41

2.59

90.26

94.41

5.59

85.54

9.74

86.47

13.53

67.79

32.21

15.91

84.09

36.98

63.02

46.75

53.25

44.61

55.39

41.46

15.9

20.56

14.52

7.56

48.91

51.09

49.21

50.79

13.37

21.11

11.79

8.8

49.46

12.79

14.16

15.46

8.13

48.02

51.98

51.85

33.33

11.74

2.79

0.28
51.07

34.67

11.72

2.2

0.34
53.9

32.91

10.52

2.39

0.28
49.14

50.86

23.56

29.92

27.26

12.38

6.88

43.3

36.34

15.89

a

a 
Mother's Education Status

Less than High School

High School (omitted)

13.97

30

Some College Degree

College Degree or above

26.44

29.6
31.5

68.5

Married

Urban Status

Not in the Urban Area

In the Urban Area

16.88

83.12
14.67

23.23

36

26.09

West

Household Income
$\$ 5,000$ or less

$\$ 5,001$ to $\$ 10,000$

$\$ 10,001$ to $\$ 15,000$

$\$ 15,001$ to $\$ 20,000$

$\$ 20,001$ to $\$ 25,000$

$\$ 25,001$ to $\$ 30,000$

$\$ 30,001$ to $\$ 35,000$

$\$ 35,001$ to $\$ 40,000$

$\$ 40,001$ to $\$ 50,000$

$\$ 50,001$ to $\$ 75,000$

$\$ 75,000$ to $\$ 100,000$

$\$ 100,001$ to $\$ 200,000$

$\$ 200,001$ or more

4.35

4.48

6.1

6.44

8.16

6.32

5.58

5.92

8.76

15.78

12.37

12.3

3.43

Mean Age of Child

Mean Age of Mother

Mean Number of children in household
12.71

33.7

28.06

25.53

37.9

62.1

23.42

76.58

52.2

47.8

6.99

27.28

43.12

24.15

44.48

25.2

6.17

Mean Number of adults in household

Note: Numbers represent percentages unless notes as means. $\mathrm{a}=$ data suppressed due to IES concerns regarding confidentiality. 
Table 2 - Logistic regression models of household and child food insecurity with and without selection correction (marginal effects)

\begin{tabular}{|c|c|c|c|c|c|c|c|c|}
\hline & \multicolumn{2}{|c|}{ Full Sample $(N=5,500)$} & \multicolumn{2}{|c|}{$\begin{array}{l}\text { Family Day-Care } \\
(\mathrm{N}=1,150) \\
\text { Househol }\end{array}$} & \multicolumn{2}{|c|}{$\begin{array}{c}\text { Center Care } \\
(\mathrm{N}=3,400) \\
\text { Household }\end{array}$} & \multicolumn{2}{|c|}{ Head Start (N=950) } \\
\hline & Household FI & $\begin{array}{c}\text { Child } \\
\text { Fl }\end{array}$ & $\begin{array}{c}\text { Househol } \\
\text { d FI }\end{array}$ & Child FI & $\mathrm{FI}$ & Child FI & $\begin{array}{c}\text { Household } \\
\mathrm{FI}\end{array}$ & $\begin{array}{c}\text { Child } \\
\mathrm{FI}\end{array}$ \\
\hline \multirow[t]{2}{*}{ Provider CACFP Participation } & 0.005 & -0.001 & 0.038 & 0.028 & 0.020 & 0.001 & -0.031 & -0.029 \\
\hline & $(0.011)$ & $(0.005)$ & $(0.032)$ & $(0.015)$ & $(0.011)$ & $(0.004)$ & $(0.053)$ & $(0.022)$ \\
\hline CACFP in Dept. of Education & -0.025 & 0.001 & -0.035 & -0.002 & -0.011 & 0.002 & $-0.070 *$ & -0.016 \\
\hline \multirow[t]{2}{*}{ Provider CACFP Participation } & 0.003 & -0.004 & 0.024 & 0.000 & 0.018 & 0.002 & -0.041 & -0.055 \\
\hline & $(0.011)$ & $(0.005)$ & $(0.025)$ & $(0.008)$ & $(0.012)$ & $(0.004)$ & $(0.051)$ & (0.033) \\
\hline \multirow[t]{2}{*}{ CACFP in Dept. of Education } & -0.016 & 0.005 & -0.006 & 0.003 & -0.001 & 0.006 & -0.103 & -0.009 \\
\hline & $(0.028)$ & $(0.005)$ & $(0.024)$ & $(0.007)$ & $(0.015)$ & $(0.004)$ & $(0.065)$ & $(0.041)$ \\
\hline
\end{tabular}

Note: All models include the lagged dependent variable, children's characteristics (age, race, gender, and health) and parental characteristics (marital status, education level, household income, region, living in an urban area, maternal age, and household composition).

IPW indicates that inverse probability weighting selection correction has been used. Additional covariates used for the propensity score correction are: center for profit, center license status, center accepts child care subsidies, center accredited and child in care 30 hours or more. A different IPW was used for each subgroup.

Each column corresponds to a different regression. We report marginal effects. Standard errors are shown in parentheses.

${ }^{*} p<.10, * * p<.05, * * * p<.01$. 
Appendix Table 1 - Logistic regression models of households with children with hunger (marginal effects)

\begin{tabular}{lccrr}
\hline & $\begin{array}{c}\text { Full } \\
\text { Sample }\end{array}$ & $\begin{array}{c}\text { Family Day- } \\
\text { Care }\end{array}$ & $\begin{array}{c}\text { Center } \\
\text { Care }\end{array}$ & $\begin{array}{c}\text { Head } \\
\text { Start }\end{array}$ \\
\hline Provider CACFP Participation & 0.000 & 0.014 & 0.003 & 0.018 \\
& $(0.005)$ & $(0.016)$ & $(0.004)$ & $(0.029)$ \\
CACFP in Dept. of Education & 0.004 & -0.002 & $0.008 *$ & -0.004 \\
& $(0.006)$ & $(0.015)$ & $(0.005)$ & $(0.020)$
\end{tabular}

Note: All models include the lagged dependent variable, children's characteristics (age, race, gender, and health) and parental characteristics (marital status, education level, household income, region, living in an urban area, maternal age, household composition).

Each column corresponds to a different regression. We report marginal effects. Standard errors are shown in parentheses.

${ }^{*} p<.10, * * p<.05, * * * p<.01$. 